\title{
Analysis of out-of-hospital cardiac arrest and ozone pollution: A qualitative study
}

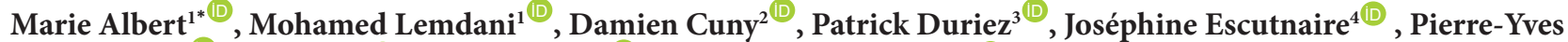

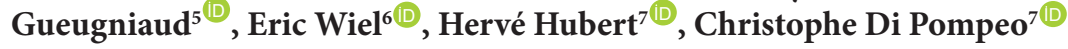 \\ ${ }^{1}$ Public Health Department, Faculty of Medicine, Univ. Lille, CHU Lille, F-59000 Lille, France \\ ${ }^{2}$ Impact of the Chemical Environment on Human Health, Faculty of Medicine, Univ. Lille, F-59000 Lille, France \\ ${ }^{3}$ Degenerative and Vascular Disorders, Faculty of Medicine, Univ. Lille, F-59000 Lille, France \\ ${ }^{4}$ Public Health Department, Faculty of Medicine, Univ. Lille, CHU Lille, F-59000 Lille, France; French National Out-of-Hospital Cardiac \\ Arrest Registry Research, RéAC, Lille, France \\ ${ }^{5}$ French National Out-of-Hospital Cardiac Arrest Registry Research, RéAC, Lille, France; SAMU 69 and Emergency Department, Lyon \\ University Hospital, Lyon, France \\ ${ }^{6}$ Public Health Department, Faculty of Medicine, Univ. Lille, CHU Lille, F-59000 Lille, France; SAMU du Nord and Emergency \\ Department for Adults, Lille University Hospital, Lille, France \\ ${ }^{7}$ Public Health Department, Faculty of Medicine, Univ. Lille, CHU Lille, F-59000 Lille, France; French National Out-of-Hospital Cardiac \\ Arrest Registry Research, RéAC, Lille, France
}

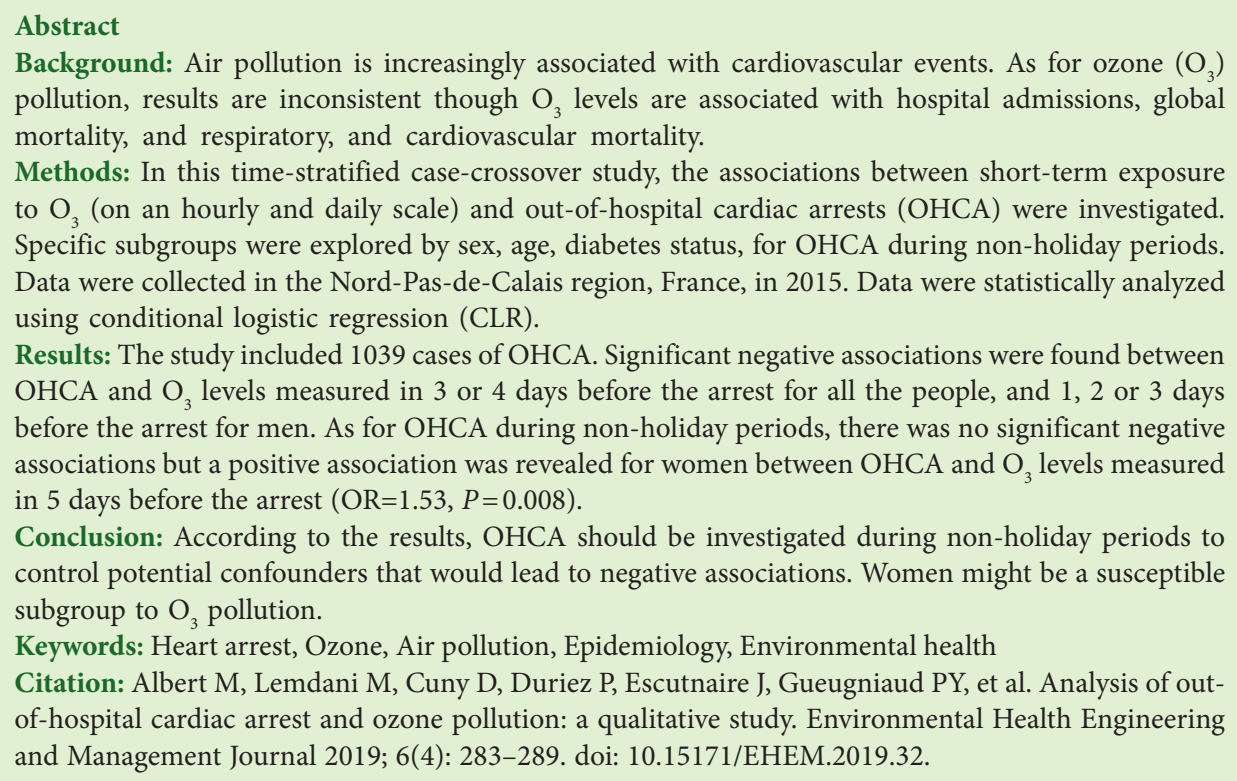

Article History:

Received: 26 August 2019

Accepted: 5 October 2019

ePublished: 27 November 2019
*Correspondence to:

Marie Albert

Email: mariealbert1@hotmail.fr

\section{Introduction}

Cardiac arrest refers to the abrupt loss of heart function and is an important public issue. The global incidence of sudden cardiac death (SCD) rates from 50 to 100 per 100000 in the general population, is between 180000 and 450000 cases annually in the United States (1). Most cardiac arrests (85\%) are out-of-hospital cardiac arrests (OHCA) (2), and the global incidence of OHCA is approximately 46000 cases per year in France. Cardiac arrests survival rates remain low: $4.9 \%$ of OHCA patients survive for at least 30 days or to hospital discharge (3). Although the risk of SCD increases with age, OHCA is a socio-economic issue because the proportion of sudden deaths is larger among young people (4).

According to the World Health Organization (WHO), outdoor air pollution is a major environmental health problem and it was estimated to cause 4.2 million premature deaths worldwide in 2016. In the literature, short-term 
exposure to air pollution is being increasingly associated with cardiovascular morbidity and mortality (5-9). In particular, positive associations were revealed between OHCA and fine particulate matter with an aerodynamic diameter under $2.5 \mu \mathrm{m}$ (PM2.5) in some studies (1013). Results for ozone $\left(\mathrm{O}_{3}\right), \mathrm{PM}$ smaller than 10 microns (PM10), carbon monoxide (CO), sulfur dioxide $\left(\mathrm{SO}_{2}\right)$, and nitrogen dioxide $\left(\mathrm{NO}_{2}\right)$, were inconsistent (12-17). More specifically, $\mathrm{O}_{3}$ levels had a positive relationship with heart failure (18), hospital admissions, global mortality (19), and respiratory and cardiovascular mortality $(19,20)$. Eight studies investigated the association between OHCA and short-term exposure to $\mathrm{O}_{3}$ levels (10-12,15,21-24). Three studies found positive associations between $\mathrm{O}_{3}$ exposure and OHCA $(15,21,24)$.

The aims of this study were to evaluate the effects of shortterm exposure to $\mathrm{O}_{3}$ (on a daily and hourly scale) on the occurrence of OHCA in Nord-Pas-de-Calais (NPdC), France. The ratio of OHCA was investigated during nonholiday periods and for susceptible subgroups (by sex, age, diabetes status) so as to arouse political commitment on air pollution control strategies for vulnerable populations. Subgroup analyses could be a good alternative to overcome the problem of the small population-wide relative risks usually observed and to control confounding effects of holidays.

\section{Materials and Methods}

Out-of-hospital cardiac arrest data

Data on OHCA were collected from the French Cardiac Arrest Registry 'Registre électronique des Arrêts Cardiaques' (RéAC). RéAC is an electronic, web-based data management system that includes patients with OHCA when a mobile medical team (MMT) is involved (25). According to the recommended guidelines for uniform reporting of data of OHCA (26), the RéAC form follows the Utstein universal style. Thus, this registry provides patients data, such as gender, age, location of the arrest, place of residence, and cardiac arrest history. The participants participated in the study voluntarily. The registry was approved as a medical assessment registry without a requirement for patient consent by the French Advisory Committee on Information Processing in Health Research (CCTIRS) and the French National Data Protection Commission (CNIL, authorization number 910946). Ten mobile emergency and resuscitation services are involved in NPdC for a population representing $71.45 \%$ of the 4.2 million inhabitants. In this study, data were collected from January 1 to December 31, 2015, in NPdC. Of 1408 cases obtained, 235 cases of the arrest that were not due to air pollution were excluded: 143 traumatic cardiac arrests, 56 pulmonary aspirations, 31 poisonings, and 5 drownings. Moreover, 134 cases were excluded because the arrest location was different from their place of residence, which was not consistent with the study design.
Ambient air quality and meteorological data

The air quality was provided by ATMO Hauts-de-France, an association approved by the Ministry of Environment, monitoring air quality with 41 stations in NPdC (11 monitoring PM2.5, 32 for PM10, 26 for $\mathrm{NO}_{2}, 21$ for $\mathrm{O}_{3}$, 14 for $\mathrm{SO}_{2}, 2$ for $\mathrm{CO}$ ). Temperature levels were collected from Météo France's website (from 16 stations in the region). In order to adjust the models, the levels of $\mathrm{O}_{3}$ as well as the levels of other regulated pollutants (PM2.5, $\mathrm{PM} 10, \mathrm{NO}_{2}, \mathrm{SO}_{2}, \mathrm{CO}$ ) and temperature, were collected. Data were collected on a daily and hourly scale for the pollutants. In accordance with the air quality criteria for $\mathrm{O}_{3}$, the daily level of $\mathrm{O}_{3}$ refers to the daily maximum 8-hour average for a day. PM2.5 and PM10 levels were obtained from gravimetric analyses, $\mathrm{NO}_{2}$ levels from chemiluminescence, $\mathrm{O}_{3}$ levels by $\mathrm{UV}$ absorption, $\mathrm{SO}_{2}$ from fluorescence absorption, and $\mathrm{CO}$ by non-dispersive infrared absorption.

\section{Study design}

To control temporal trends of air pollution levels and OHCA incidence, this time-stratified case-crossover study was conducted. This design applies in the cases of brief exposures, transient changes in risk, and rare acute-onset diseases (27). It consists in confronting the exposure of the patients during a risk period to that during a reference period. The latter has to be chosen according to a number of constraints to control biases that could be resulted from long-term time trends, seasonal patterns, day-of-the-week effects, and autocorrelation of exposures. Thus, measures have to be assessed on the same day-of-the-week in the same month of the same year of the arrest (17,28-30). As an illustration, if the OHCA occurs on Saturday in March, the risk exposure will be measured on that day and will be compared to the reference exposures measured on all other Saturdays in March. As a result, stable personality traits are controlled over time. If a value was missing either for the risk exposure or for its reference exposures, therefore, the case was excluded.

\section{Subgroups}

Subgroup analyses were also conducted. In this study, it was focused on the occurrence of OHCA during nonholiday periods at different levels of pollutants (31). Then, subgroups of sex, age ( 50 to 75 years old versus over 75 years old, following recommendations made in June 2010 by the French Center for Strategic Analysis, Centre D'Anlayse Stratégique), and diabetes status were investigated. In 2015 , there were six holiday periods: from January 1 to 4, from February 21 to March 8, from April 25 to May 10, from July 4 to August 30, from October 17 to November 1 , and from December 19 to 31 . OHCA events occurring during non-holiday periods were excluded whenever less than two values were available for the reference exposures or if the value for the risk exposure was missed. 


\section{Lag times}

In the present study, short-time effects of pollutants on the occurrence of OHCA were evaluated. Therefore, risk exposures were measured at different lag times close to the time of the OHCA: lag0h (for the hour of the OHCA), CA4h (from lag0h to lag3h, for the mean of the hour of the arrest and the three hours before the arrest), CAH12 (mean from lag0h to lag11h), lag0d (for the day of the OHCA) to lag5d (five days before the OHCA). If more than $25 \%$ of the values needed to compute the exposure for CA4h or CA12h were missing, the exposure was considered as missing.

\section{Statistical analyses}

To estimate odds ratios (OR) with 95\% confidence intervals (CI) per interquartile range (IQR) increase, conditional logistic regression was used. First, a singlepollutant model with $\mathrm{O}_{3}$, which was adjusted on temperature using a nonparametric smoothing spline of degree 3 with 4 knots optimally chosen, was built (32-36). If the evaluated lag time was statistically significant at $P=0.01$, which provides very strong evidence (37) because of the multiple statistical tests, a multi-pollutant model was used. This multi-pollutant model was built by adding pollutants with concentrations moderately correlated with $\mathrm{O}_{3}$ concentrations (absolute value of Spearman correlations, $r=0.40-0.60)$ as a bias-variance trade-off. Thus, multi-pollutant models included $\mathrm{O}_{3}, \mathrm{PM} 2.5, \mathrm{NO}_{2}$, and temperature. The same lag times were used for all concentrations within a model except for the hourly scale, in which the daily level was used for the temperature level. Data were statistically analyzed using the $\mathrm{R}$ statistical software (R Core Team, 2015).

Results

This study included 1039 cases of OHCA, $60.1 \%$ of which were men $(n=624), 46.4 \%$ aged 50 to 75 years $(n=482)$, $40.7 \%$ aged over 75 years $(n=423)$, and $16.4 \%$ were diabetic patients $(n=170)$. Air pollution and temperature data for OHCA in 2015 and during non-holiday periods are summarized in Table 1. On the day of the OHCA incidence, $\mathrm{O}_{3}$ levels were moderately correlated with PM2.5 levels $(r=-0.44)$ and $\mathrm{NO}_{2}$ levels $(r=-0.59)$; multipollutant models were then obtained by adding PM2.5 and $\mathrm{NO}_{2}$.

Table 2 shows the values for significant results at the 1\% level of significance for single-pollutant models and then for multi-pollutant models. Figures 1 to 4 describe OR and 95\% CI of single-pollutant models for the OHCA all year long (Figures 1 and 3) or for non-holiday OHCA (Figures 2 and 4) and for lag0h to lag0d (Figures 1 and 2) or for lag1d to lag5d (Figures 3 and 4).

While exploring the shortest lag times (on the day of the OHCA: lag0h, CA4h, CA12h, and lag0d), no significant association neither with OHCA all year long nor with non-holiday OHCA was found. While exploring longer lag times (from lag1d to lag5d), mainly negative associations were found with OHCA all year long (significant at lag3d and lag4d) and in men (significant at both lag1d and lag2d in multi-pollutant models, and at lag3d). The most significant associations were found in men at lag $1 \mathrm{~d}$ and lag2d $(\mathrm{OR}=0.74, P=0.004)$. The only positive association was found with non-holiday OHCA at the longest lag time (lag5d) in women $(\mathrm{OR}=1.53, P=0.008)$.

\section{Discussion}

In the literature, three studies found positive associations with lag times taking into account the exposure the day of the OHCA (CA2h, CA24h, and CA72h or mean of lag2h, lag3h, and lag0d) $(15,21,24)$. In the present study, no significant association at those short lag times was found. Moreover, the significant associations were mainly negative,

Table 1. Description of data $\left(\mu \mathrm{g} / \mathrm{m}^{3}\right.$ for pollutants, ${ }^{\circ} \mathrm{C}$ for temperature $)$

\begin{tabular}{|c|c|c|c|c|c|}
\hline & Mean (SD) & Median & $\mathrm{IQR}^{\mathrm{b}}$ & Number of OHCA (\%) ${ }^{c}$ & Number of Non-holiday OHCA (\%) \\
\hline \multicolumn{6}{|c|}{ Hour of the OHCA } \\
\hline PM2.5 & $15.03(13.57)$ & 11.10 & 12.00 & $560(54 \%)$ & $377(36 \%)$ \\
\hline PM10 & $22.24(15.41)$ & 18.60 & 15.50 & $580(56 \%)$ & $388(37 \%)$ \\
\hline $\mathrm{NO}_{2}$ & $21.95(16.12)$ & 18.10 & 20.82 & 614 (59\%) & 413 (40\%) \\
\hline $\mathrm{O}_{3}$ & $46.65(25.19)$ & 47.10 & 37.65 & $616(59 \%)$ & $401(39 \%)$ \\
\hline $\mathrm{SO}_{2}$ & $2.59(6.85)$ & 1.50 & 2.00 & $326(31 \%)$ & 307 (30\%) \\
\hline $\mathrm{CO}$ & $0.24(0.26)$ & 0.20 & 0.17 & $425(41 \%)$ & $329(32 \%)$ \\
\hline \multicolumn{6}{|c|}{ Day of the OHCA } \\
\hline PM2.5 & $14.70(10.52)$ & 11.50 & 10.00 & $814(78 \%)$ & $529(51 \%)$ \\
\hline PM10 & $21.84(11.96)$ & 18.80 & 12.42 & $848(82 \%)$ & $555(53 \%)$ \\
\hline $\mathrm{NO}_{2}$ & $20.98(11.80)$ & 19.40 & 16.80 & 912 (88\%) & $584(56 \%)$ \\
\hline $\mathrm{O}_{3}$ & $64.51(23.21)$ & 64.85 & 27.94 & $850(82 \%)$ & $538(52 \%)$ \\
\hline $\mathrm{SO}_{2}$ & $2.15(3.12)$ & 1.50 & 1.80 & $610(59 \%)$ & 485 (47\%) \\
\hline $\mathrm{CO}$ & $0.23(0.16)$ & 0.21 & 0.15 & 707 (68\%) & $516(50 \%)$ \\
\hline Temperature & 11.08 (5.39) & 11.30 & 7.50 & 1026 (99\%) & 609 (59\%) \\
\hline
\end{tabular}

a Standard deviation; ${ }^{\mathrm{b}}$ Interquartile range; ${ }^{\mathrm{C}}$ Without missing values for the pollutant. 
Table 2. Significant associations $(P<0.01)$ between $\mathrm{O}_{3}$ levels and OHCA incidence

\begin{tabular}{|c|c|c|c|c|c|}
\hline \multirow{2}{*}{ Lag } & \multirow{2}{*}{ Subgroup } & \multicolumn{2}{|c|}{$\mathrm{O}_{3}$ - Single-pollutant Model } & \multicolumn{2}{|c|}{$\mathrm{O}_{3}-$ Multi-pollutant Model } \\
\hline & & OR per IQR $(95 \%$ IC) & $P$ value & OR per IQR $(95 \%$ IC) & $P$ value \\
\hline \multicolumn{6}{|c|}{ OHCA all year long } \\
\hline Lag1d & Male & $0.74(0.60-0.91)$ & 0.004 & $0.71(0.55-0.91)$ & 0.008 \\
\hline Lag2d & Male & $0.74(0.61-0.91)$ & 0.004 & $0.67(0.52-0.87)$ & 0.002 \\
\hline \multirow[t]{2}{*}{$\operatorname{Lag} 3 d$} & All & $0.81(0.69-0.94)$ & 0.006 & - & - \\
\hline & Male & $0.75(0.61-0.92)$ & 0.005 & - & - \\
\hline Lag4d & All & $0.81(0.69-0.95)$ & 0.008 & - & - \\
\hline \multicolumn{6}{|c|}{ Non-holiday OHCA } \\
\hline Lag5d & Female & $1.53(1.12-2.11)$ & 0.008 & - & - \\
\hline
\end{tabular}

which can be explained by confounding factors, such as PM2.5 levels and holiday periods. Indeed, PM2.5 and $\mathrm{O}_{3}$ levels are negatively correlated $(\mathrm{r}=-0.44)$. Moreover, $\mathrm{O}_{3}$ is a secondary pollutant formed through a photochemical reaction requiring sunlight, and $\mathrm{O}_{3}$ local concentrations are reduced in the vicinity of heavy vehicular traffic due to scavenging by $\mathrm{NO}$ and volatile organic compounds (38), which could contribute to higher $\mathrm{O}_{3}$ levels during summer holidays. Thus, in this study, no negative association was found using multi-pollutant models or focusing on non-

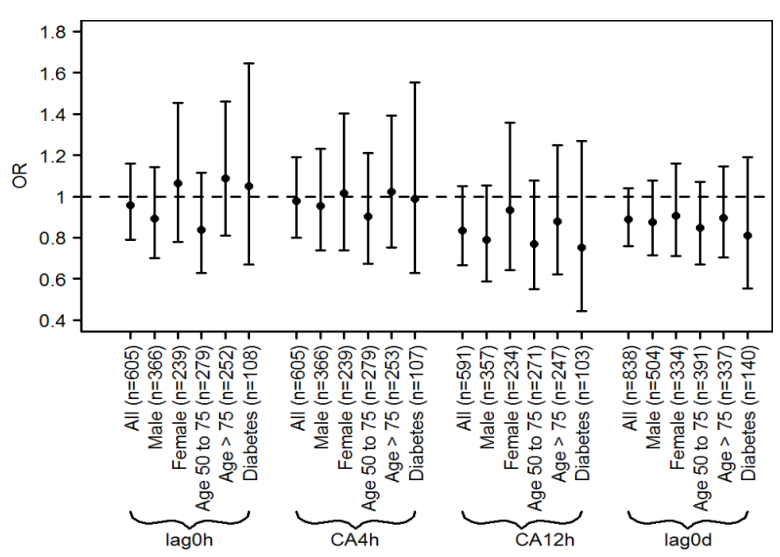

Figure 1. OR and $95 \% \mathrm{Cl}$ for $\mathrm{OHCA}$ versus $\mathrm{O}_{3}$ levels for lag0h to lag0d.

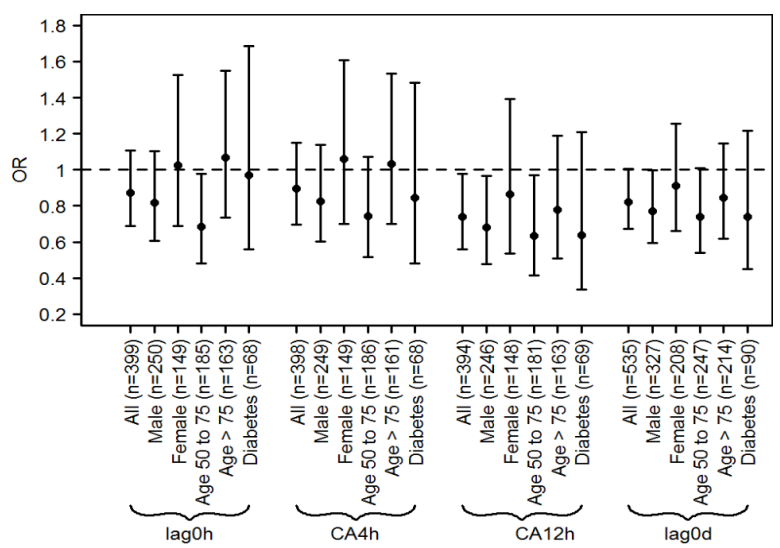

Figure 2. $\mathrm{OR}$ and $95 \% \mathrm{Cl}$ for non-holiday $\mathrm{OHCA}$ versus $\mathrm{O}_{3}$ levels for lag0h to lag0d. holiday OHCA. Furthermore, in the literature, from lag0h to lag5d, studies on $\mathrm{O}_{3}$ positive associations showed no association between PM2.5 and OHCA $(15,21)$, also studies on PM2.5 positive associations, showed no association between $\mathrm{O}_{3}$ and OHCA $(10,12,22,23)$. Negative associations could also be due to a reduction in the number of people at risk, as $\mathrm{O}_{3}$ levels may increase respiratory mortality $(19,20)$. Although confounding factors can account for the negative associations, some studies reported the association between heart protective

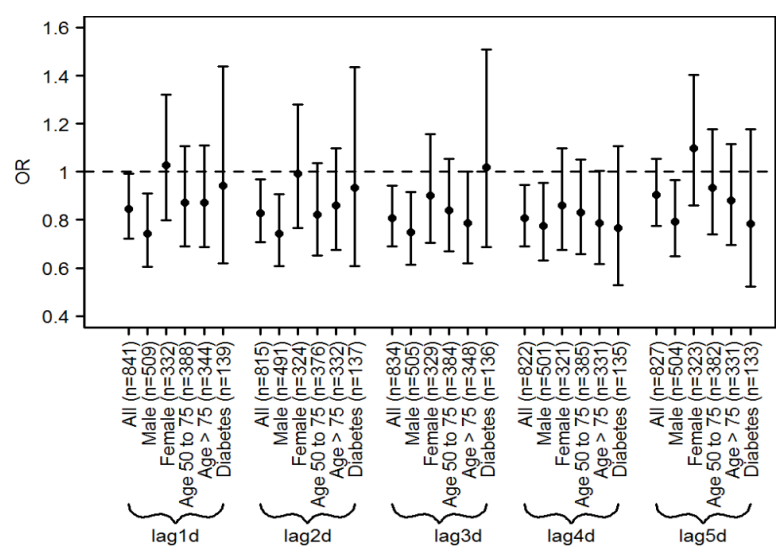

Figure 3. OR and $95 \% \mathrm{Cl}$ for $\mathrm{OHCA}$ versus $\mathrm{O}_{3}$ levels for lag1d to lag5d.

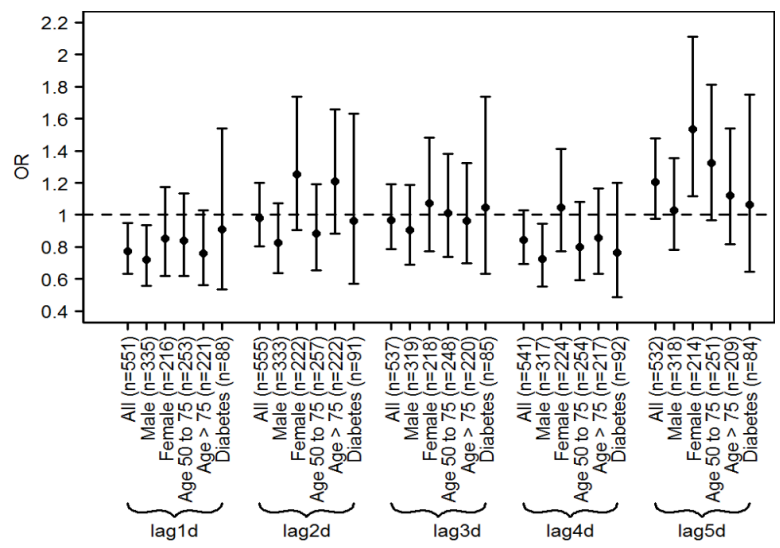

Figure 4. OR and $95 \% \mathrm{CI}$ for non-holiday $\mathrm{OHCA}$ versus $\mathrm{O}_{3}$ levels for lag1d to lag5d. 
effects of $\mathrm{O}_{3}$ with an increase in vasodilation (39), and an infarct size reduction (40). In the present study, a positive association was found when considering nonholiday OHCA in women. No significant associations were found among men, the 50-75 year old age group, and patients with diabetes. Indeed, we have previously shown positive associations between PM2.5 and OHCA among men, the 50-75 year old age group, and patients with diabetes whereas there were no associations between PM2.5 and OHCA among women (41). Two studies have found positive associations between $\mathrm{O}_{3}$ and OHCA among women, suggesting hormonal cause $(42,43)$. It is worth mentioning that there are various mechanisms of $\mathrm{O}_{3}$ toxicity. An increased airway permeability reported by the measure of the pulmonary clearance of radioisotopelabeled organic molecule, ( $\left.{ }^{99 \mathrm{~m}} \mathrm{TC}-\mathrm{DTPA}\right)$, could increase the uptake of other toxicants or the release of inflammatory cells $(44,45)$. Some studies have shown inflammatory processes with changes in cyclooxygenase metabolites of arachidonic acid (46), and with neutrophil influx into the airways (46-48). A stimulation of fibrinogenic processes was reported with higher levels of fibronectin, factor VII, and urokinase plasminogen activator (47). In a study, ultrafine carbon particles increased sympathetic nervous system activity and more so with added $\mathrm{O}_{3}$ (48). $\mathrm{O}_{3}$ may also lead to an increase in myocardial work and impairment of pulmonary gas exchange (49). In the study of $\mathrm{O}_{3}$ effects, special consideration should be given to healthy people who exercise regularly outdoors, because of higher $\mathrm{O}_{3}$ exposure, and those with asthma, because of increased symptomatic responses $(19,50)$.

Most of the significant associations were found with OHCA occurring all year long. The significance of those associations may be due to temporal trends of $\mathrm{O}_{3}$ pollution with different levels during holidays. However, by considering non-holiday OHCA, the periods in which $\mathrm{O}_{3}$ pollution may impact health differently, were excluded. In addition, we have to be cautious when drawing conclusions with single-pollutant models because a pollutant level serves as a surrogate term for a complex mixture of pollutants, and ozone pollution may better reflect particulate matter personal exposure than exposure to $\mathrm{O}_{3}$ itself (51). However, results from multi-pollutant models are also limited by overfitting (of correlated pollutant levels) or interactions (synergistic effects of $\mathrm{O}_{3}$ and particulate matter) (52). Wherever the OHCA occurs (indoor, outdoor), the individual pollution exposure is given by measures of ATMO Hauts-de-France monitors which could result in imprecise results. Interpretation of the results of this study compared to the results of other studies is limited. The precision of the results depends on the number of monitors available, the number of cases included, and criteria used to define a case and pollution levels. Variability in pollution levels and composition makes it difficult to compare results obtained from different study periods and regions.

\section{Conclusion}

The investigation of the relationship between $\mathrm{O}_{3}$ levels and the occurrence of OHCA showed mainly negative associations on the daily scale. There were no negative associations between $\mathrm{O}_{3}$ levels and the occurrence of OHCA during non-holiday periods, but a positive association was reported between the occurrence of OHCA during non-holiday periods and $\mathrm{O}_{3}$ levels five days before the OHCA, among women. Therefore, it would be interesting to analyze non-holiday OHCA to estimate health impact of exposure to ozone, in order to control for confounders, such as temporal trends and PM2.5 levels. The negative associations could also be due to the heart protective effect of $\mathrm{O}_{3}$ and further investigation is necessary. Moreover, a special attention should be paid to the subgroup of women, for which the only positive association was found. Analyses of susceptible subgroups might show associations that do not usually appear because of the small population-wide relative risks and could lead to revised recommendations for the subgroups. Further studies under similar conditions are needed to assess the significance of the results of the present study. As a final point, models taking into account confounders should be further developed so as to evaluate the impact of $\mathrm{O}_{3}$ itself.

\section{Acknowledgments}

The authors would like to thank the French Cardiac Arrest Registry (RéAC). The RéAC registry was supported by the French Society of Emergency Medicine (SFMU), a patient foundation - Fédération Française de Cardiologie, the Mutuelle Générale de l'Education Nationale (MGEN), the University of Lille, and the Institute of Health Engineering of Lille. The authors declare that the funding sources had no role in conducting, analysis and interpretation of data or writing the manuscript. And special thanks to the Heart and Arteries Foundation for its financial support.

\section{Ethical issues}

The approval of the Ethics Committee was not necessary, because explorations were based on anonymized patient data.

\section{Competing interests}

The authors declare that they have no competing interests.

\section{Authors' contributions}

All authors were equally involved in the conception and design, analysis and interpretation of data, drafting of the article or revising it critically for important intellectual content, and manuscript approval.

\section{References}

1. Deo R, Albert CM. Epidemiology and genetics of sudden cardiac death. Circulation 2012; 125(4): 620-37. doi: 10.1161/circulationaha.111.023838. 
2. Gueugniaud PY, Bertrand C, Savary D, Hubert H. [Cardiac arrest in France: Why a national register?]. Presse Med 2011; 40(6): 634-8. doi: 10.1016/j.lpm.2011.02.026. [In French].

3. Luc G, Baert V, Escutnaire J, Genin M, Vilhelm C, Di Pompéo C, et al. Epidemiology of out-of-hospital cardiac arrest: a French national incidence and mid-term survival rate study. Anaesth Crit Care Pain Med 2019; 38(2): 131-5. doi: 10.1016/j.accpm.2018.04.006.

4. Krahn AD, Connolly SJ, Roberts RS, Gent M. Diminishing proportional risk of sudden death with advancing age: implications for prevention of sudden death. Am Heart J 2004; 147(5): 837-40. doi: 10.1016/j.ahj.2003.12.017.

5. Bell ML, McDermott A, Zeger SL, Samet JM, Dominici F. Ozone and short-term mortality in 95 US urban communities, 1987-2000. JAMA 2004; 292(19): 2372-8. doi: $\quad$ 10.1001/jama.292.19.2372.

6. Forastiere F, Stafoggia M, Picciotto S, Bellander T, D'Ippoliti $\mathrm{D}$, Lanki $\mathrm{T}$, et al. A case-crossover analysis of out-ofhospital coronary deaths and air pollution in Rome, Italy. Am J Respir Crit Care Med 2005; 172(12): 1549-55. doi: 10.1164/rccm.200412-1726OC.

7. Pope CA 3rd, Dockery DW. Health effects of fine particulate air pollution: lines that connect. J Air Waste Manag Assoc 2006; 56(6): 709-42. doi: 10.1080/10473289.2006.10464485.

8. Brook RD, Rajagopalan S, Pope CA 3rd, Brook JR, Bhatnagar A, Diez-Roux AV, et al. Particulate matter air pollution and cardiovascular disease: an update to the scientific statement from the American Heart Association. Circulation 2010; 121(21): 2331-78. doi: 10.1161/CIR.0b013e3181dbece1.

9. Peters A, Dockery DW, Muller JE, Mittleman MA. Increased particulate air pollution and the triggering of myocardial infarction. Circulation 2001; 103(23): 2810-5. doi: 10.1161/01.cir.103.23.2810.

10. Dennekamp M, Akram M, Abramson MJ, Tonkin A, Sim MR, Fridman M, et al. Outdoor air pollution as a trigger for out-of-hospital cardiac arrests. Epidemiology 2010; 21(4): 494-500. doi: 10.1097/EDE.0b013e3181e093db.

11. Silverman RA, Ito K, Freese J, Kaufman BJ, De Claro D, Braun J, et al. Association of ambient fine particles with out-of-hospital cardiac arrests in New York City. Am J Epidemiol 2010; 172(8): 917-23. doi: 10.1093/aje/kwq217.

12. Wichmann J, Folke F, Torp-Pedersen C, Lippert F, Ketzel $\mathrm{M}$, Ellermann T, et al. Out-of-hospital cardiac arrests and outdoor air pollution exposure in Copenhagen, Denmark. PLoS One 2013; 8(1): e53684. doi: 10.1371/journal. pone.0053684.

13. Xia R, Zhou G, Zhu T, Li X, Wang G. Ambient air pollution and out-of-hospital cardiac arrest in Beijing, China. Int J Environ Res Public Health 2017; 14(14): pii: E423. doi: 10.3390/ijerph14040423.

14. Rosenthal FS, Kuisma M, Lanki T, Korhonen M, Hussein T, Pekkanen J. Particulate air pollution triggers cardiac arrest in Helsinki--effect of medical history and two-pollutant analysis. Epidemiology 2011; 22(1): S53. doi: 10.1097/01. ede.0000391825.03966.79

15. Ensor KB, Raun LH, Persse D. A case-crossover analysis of out-of-hospital cardiac arrest and air pollution. Circulation 2013; 127(11): 1192-9. doi: 10.1161/ circulationaha.113.000027.

16. Rosenthal FS, Kuisma M, Lanki T, Hussein T, Boyd J, Halonen JI, et al. Association of ozone and particulate air pollution with out-of-hospital cardiac arrest in Helsinki, Finland: evidence for two different etiologies. J Expo Sci Environ Epidemiol 2013; 23(3): 281-8. doi: 10.1038/ jes.2012.121.

17. Levy D, Lumley T, Sheppard L, Kaufman J, Checkoway H. Referent selection in case-crossover analyses of acute health effects of air pollution. Epidemiology 2001; 12(2): 186-92. doi: 10.1097/00001648-200103000-00010.

18. Pothirat C, Chaiwong W, Liwsrisakun C, Bumroongkit C, Deesomchok A, Theerakittikul T, et al. Acute effects of air pollutants on daily mortality and hospitalizations due to cardiovascular and respiratory diseases. J Thorac Dis 2019; 11(7): 3070-83. doi: 10.21037/jtd.2019.07.37.

19. Lippmann M. Ozone. In: Lippmann M. Environmental Toxicants. 3rd ed. US: Wiley-Blackwell; 2008. p. 869-936. doi: $10.1002 / 9780470442890 . c h 23$.

20. Raza A, Dahlquist M, Lind T, Ljungman PL. Susceptibility to short-term ozone exposure and cardiovascular and respiratory mortality by previous hospitalizations. Environ Health 2018; 17(1): 37. doi: 10.1186/s12940-018-0384-z.

21. Raza A, Bellander T, Bero-Bedada G, Dahlquist M, Hollenberg J, Jonsson M, et al. Short-term effects of air pollution on out-of-hospital cardiac arrest in Stockholm. Eur Heart J 2014; 35(13): 861-8. doi: 10.1093/eurheartj/ eht489.

22. Straney L, Finn J, Dennekamp M, Bremner A, Tonkin A, Jacobs I. Evaluating the impact of air pollution on the incidence of out-of-hospital cardiac arrest in the Perth Metropolitan Region: 2000-2010. J Epidemiol Community Health 2014; 68(1): 6-12. doi: 10.1136/jech-2013-202955.

23. Kang SH, Heo J, Oh IY, Kim J, Lim WH, Cho Y, et al. Ambient air pollution and out-of-hospital cardiac arrest. Int J Cardiol 2016; 203: 1086-92. doi: 10.1016/j.ijcard.2015.11.100.

24. Raza A, Dahlquist M, Jonsson M, Hollenberg J, Svensson L, Lind T, et al. Ozone and cardiac arrest: the role of previous hospitalizations. Environ Pollut 2019; 245: 1-8. doi: $\quad 10.1016 /$ j.envpol.2018.10.042.

25. Hubert H, Tazarourte K, Wiel E, Zitouni D, Vilhelm C, Escutnaire J, et al. Rationale, methodology, implementation, and first results of the French out-of-hospital cardiac arrest registry. Prehosp Emerg Care 2014; 18(4): 511-9. doi: 10.3109/10903127.2014.916024.

26. Cummins RO, Chamberlain DA, Abramson NS, Allen M, Baskett PJ, Becker L, et al. Recommended guidelines for uniform reporting of data from out-of-hospital cardiac arrest: the Utstein Style. A statement for health professionals from a task force of the American Heart Association, the European Resuscitation Council, the Heart and Stroke Foundation of Canada, and the Australian Resuscitation Council. Circulation 1991; 84(2): 960-75. doi: 10.1161/01. cir.84.2.960.

27. Maclure M. The case-crossover design: a method for studying transient effects on the risk of acute events. Am J Epidemiol 1991; 133(2): 144-53. doi: 10.1093/ oxfordjournals.aje.a115853.

28. Levy D, Sheppard L, Checkoway H, Kaufman J, Lumley T, Koenig J, et al. A case-crossover analysis of particulate matter air pollution and out-of-hospital primary cardiac arrest. Epidemiology 2001; 12(2): 193-9.

29. Lumley T, Levy D. Bias in the case - crossover design: implications for studies of air pollution. 
Environmetrics 2000; 11(6): 689-704. doi: $10.1002 / 1099-095 \times(200011 / 12) 11: 6<689:: a i d-$ env439>3.0.co;2-n.

30. Janes H, Sheppard L, Lumley T. Case-crossover analyses of air pollution exposure data: referent selection strategies and their implications for bias. Epidemiology 2005; 16(6): 71726. doi: 10.1097/01.ede.0000181315.18836.9d.

31. Tan PH, Chou C, Liang JY, Chou CCK, Shiu CJ. Air pollution "holiday effect" resulting from the Chinese New Year. Atmos Environ 2009; 43(13): 2114-24. doi: 10.1016/j. atmosenv.2009.01.037.

32. Basu R, Samet JM. Relation between elevated ambient temperature and mortality: a review of the epidemiologic evidence. Epidemiol Rev 2002; 24(2): 190-202. doi: 10.1093/ epirev/mxf007.

33. Braga AL, Zanobetti A, Schwartz J. The time course of weather-related deaths. Epidemiology 2001; 12(6): 662-7. doi: 10.1097/00001648-200111000-00014.

34. Curriero FC, Heiner KS, Samet JM, Zeger SL, Strug L, Patz JA. Temperature and mortality in 11 cities of the eastern United States. Am J Epidemiol 2002; 155(1): 80-7. doi: 10.1093/aje/155.1.80.

35. Stafoggia M, Forastiere F, Agostini D, Biggeri A, Bisanti L, Cadum E, et al. Vulnerability to heat-related mortality: a multicity, population-based, case-crossover analysis. Epidemiology 2006; 17(3): 315-23. doi: 10.1097/01. ede.0000208477.36665.34.

36. Eilers PHC, Marx BD. Flexible smoothing with B-splines and penalties. Stat Sci 1996; 11(2): 89-121.

37. Arsham H. Kuiper's P-value as a measuring tool and decision procedure for the goodness-of-fit test. J Appl Stat 1988; 15(2): 131-5. doi: 10.1080/02664768800000020.

38. Karnosky DF, Percy KE, Chappelka AH, Simpson C, Pikkarainen J. Air pollution, global change and forests in the new millennium. Amsterdam: Elsevier Science; 2003.

39. Barath S, Langrish JP, Lundback M, Bosson JA, Goudie C, Newby DE, et al. Short-term exposure to ozone does not impair vascular function or affect heart rate variability in healthy young men. Toxicol Sci 2013; 135(2): 292-9. doi: 10.1093/toxsci/kft157.

40. Di Filippo C, Marfella R, Capodanno P, Ferraraccio F, Coppola L, Luongo M, et al. Acute oxygen-ozone administration to rats protects the heart from ischemia reperfusion infarct. Inflamm Res 2008; 57(10): 445-9. doi: 10.1007/s00011-008-7237-0.

41. Albert M, Lemdani M, Cuny D, Duriez P, Escutnaire J, Gueugniaud PY, et al. A case crossover analysis of out-ofhospital cardiac arrest and particulate matter air pollution: investigation of specific subgroups. Open Access Library Journal 2017; 4(12):1-14. doi: 10.4236/oalib.1104143

42. Zhang Y, Huang W, London SJ, Song G, Chen G, Jiang L, et al. Ozone and daily mortality in Shanghai, China. Environ Health Perspect 2006; 114(8): 1227-32. doi: 10.1289/ ehp.9014.

43. Medina-Ramón M, Schwartz J. Who is more vulnerable to die from ozone air pollution? Epidemiology 2008; 19(5): 672-9. doi: 10.1097/EDE.0b013e3181773476.

44. Kehrl HR, Vincent LM, Kowalsky RJ, Horstman DH, O’Neil JJ, McCartney WH, et al. Ozone exposure increases respiratory epithelial permeability in humans. Am Rev Respir Dis 1987; 135(5): 1124-8. doi: 10.1164/ arrd.1987.135.5.1124.

45. Foster WM, Stetkiewicz PT. Regional clearance of solute from the respiratory epithelia: $18-20 \mathrm{~h}$ postexposure to ozone. J Appl Physiol (1985) 1996; 81(3): 1143-9. doi: 10.1152/jappl.1996.81.3.1143.

46. Seltzer J, Bigby BG, Stulbarg M, Holtzman MJ, Nadel JA, Ueki IF, et al. O3-induced change in bronchial reactivity to methacholine and airway inflammation in humans. J Appl Physiol (1985) 1986; 60(4): 1321-6. doi: 10.1152/ jappl.1986.60.4.1321.

47. Koren HS, Devlin RB, Becker S, Perez R, McDonnell WF. Time-dependent changes of markers associated with inflammation in the lungs of humans exposed to ambient levels of ozone. Toxicol Pathol 1991; 19(4 Pt 1): 406-11. doi: 10.1177/0192623391019004-109.

48. Heusser K, Tank J, Holz O, May M, Brinkmann J, Engeli S, et al. Ultrafine particles and ozone perturb norepinephrine clearance rather than centrally generated sympathetic activity in humans. Sci Rep 2019; 9(1): 3641. doi: 10.1038/ s41598-019-40343-w.

49. Gong H Jr, Bedi JF, Horvath SM. Inhaled albuterol does not protect against ozone toxicity in nonasthmatic athletes. Arch Environ Health 1988; 43(1): 46-53. doi: 10.1080/00039896.1988.9934373.

50. Rundell KW, Smoliga JM, Bougault V. Exercise-induced bronchoconstriction and the air we breathe. Immunol Allergy Clin North Am 2018; 38(2): 183-204. doi: 10.1016/j. iac.2018.01.009.

51. Vedal S, Kaufman JD. What does multi-pollutant air pollution research mean? Am J Respir Crit Care Med 2011; 183(1): 4-6. doi: 10.1164/rccm.201009-1520ED.

52. Bosson J, Pourazar J, Forsberg B, Adelroth E, Sandström T, Blomberg A. Ozone enhances the airway inflammation initiated by diesel exhaust. Respir Med 2007; 101(6): 11406. doi: 10.1016/j.rmed.2006.11.010. 